\title{
Psychiatric disorders, comorbidity, and suicidality in Mexico
}

\section{Citation}

Borges, Guilherme, Matthew K. Nock, Maria Elena Medina-Mora, Irving Hwang, and Ronald C. Kessler. 2010. "Psychiatric Disorders, Comorbidity, and Suicidality in Mexico." Journal of Affective Disorders 124, nos. 1-2: 98-107.

\section{Published Version}

doi:10.1016/j.jad.2009.10.022

\section{Permanent link}

http://nrs.harvard.edu/urn-3:HUL.InstRepos:14117744

\section{Terms of Use}

This article was downloaded from Harvard University's DASH repository, and is made available under the terms and conditions applicable to Open Access Policy Articles, as set forth at http:// nrs.harvard.edu/urn-3:HUL.InstRepos:dash.current.terms-of-use\#OAP

\section{Share Your Story}

The Harvard community has made this article openly available.

Please share how this access benefits you. Submit a story.

Accessibility 


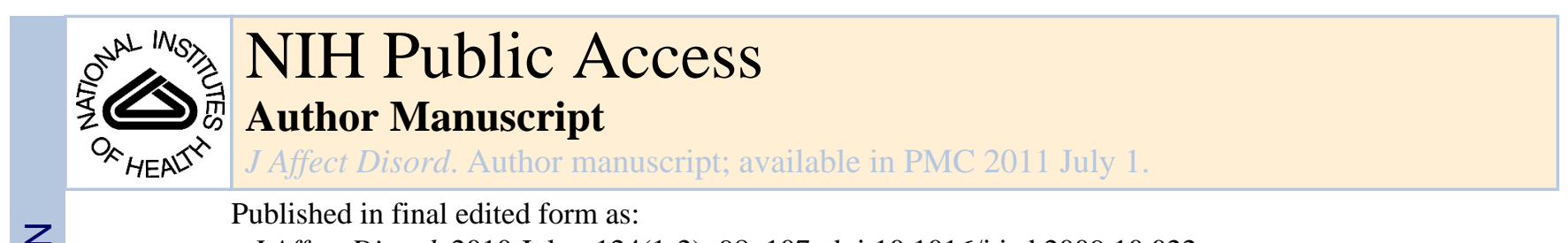

Published in final edited form as:

J Affect Disord. 2010 July ; 124(1-2): 98-107. doi:10.1016/j.jad.2009.10.022.

\title{
Psychiatric Disorders, Comorbidity, and Suicidality in Mexico
}

\author{
Guilherme Borges, Sc.D. ${ }^{1}$, \\ National Institute of Psychiatry, Mexico City \\ Matthew K. Nock, Ph.D., \\ Harvard University, Cambridge, MA \\ Maria Elena Medina-Mora, Ph.D., \\ National Institute of Psychiatry, Mexico City \\ Irving Hwang, M.A., and \\ Harvard Medical School, Boston, MA \\ Ronald C. Kessler, Ph.D. \\ Harvard Medical School, Boston, MA
}

\begin{abstract}
Background-Prior studies have reported that psychiatric disorders are among the strongest predictors of suicidal behavior (i.e., suicide ideation, plans, and attempts). However, surprisingly little is known about the independent associations between each disorder and each suicidal behavior due to a failure to account for comorbidity.
\end{abstract}

Methods-This study used data from a representative sample of 5,782 respondents participating in the Mexican National Comorbidity Survey (2001-2002) to examine the unique associations between psychiatric disorders and suicidality.

Results-A prior psychiatric disorder was present in $48.8 \%$ of those with a suicide ideation and in $65.2 \%$ of those with an attempt. Discrete-time survival models adjusting for comorbidity revealed that conduct disorder and alcohol abuse/dependence were the strongest predictors of a subsequent

\footnotetext{
(C) 2009 Elsevier B.V. All rights reserved.

${ }^{1}$ Instituto Nacional de Psiquiatria, Calzada Mexico Xochimilco No 101- Col. San Lorenzo Huipulco, Mexico D.F. C.P.14370, Mexico; tel (52 55) 5573-11-78; fax (52 55) 5513-3446; guibor@imp.edu.mx

Guilherme Borges Conceived the study, collected data, analyzed the data, and wrote initial draft and the final version.

Matthew K. Nock Conceived the study, edited prior versions and wrote the final version

Maria Elena Medina-Mora Conceived the study, collected data, and wrote the final version.

Irving Hwang Analyzed the data, and wrote initial draft and the final version

Ronal C Kessler Conceived the study and wrote the final version

IRB.

An oral and written explanation of the study was given to respondents. Interviews were administered only to those participants for whom a signed informed consent was obtained. All study participants were left a mental health resources card with contact information for different institutions where they could seek services should they wish to do so. The Human Subjects Committee of the National Institute of Psychiatry approved the recruitment, consent and field procedures.

Conflict of Interest.

Dr. Kessler has been a consultant for GlaxoSmithKline Inc., Kaiser Permanente, Pfizer Inc., Sanofi-Aventis, Shire Pharmaceuticals, and Wyeth-Ayerst; has served on advisory boards for Eli Lilly \& Company and Wyeth-Ayerst; and has had research support for his epidemiological studies from Bristol-Myers Squibb, Eli Lilly \& Company, GlaxoSmithKline, Johnson \& Johnson Pharmaceuticals, Ortho-McNeil Pharmaceuticals Inc., Pfizer Inc., and Sanofi-Aventis.

All other authors state that there are no conflict of interest.

Publisher's Disclaimer: This is a PDF file of an unedited manuscript that has been accepted for publication. As a service to our customers we are providing this early version of the manuscript. The manuscript will undergo copyediting, typesetting, and review of the resulting proof before it is published in its final citable form. Please note that during the production process errors may be discovered which could affect the content, and all legal disclaimers that apply to the journal pertain.
} 
suicide attempt. Most disorders predicted suicidal ideation but few predicted the transition from ideation to a suicide plan or attempt.

Limitations-M-NCS is a household survey that excluded homeless and institutionalized people, andthe diagnostic instrument used did not include an assessment of all DSM-IV disorders which would increase the comorbidity discussed here.

Conclusions-These results reveal a complex pattern of associations in which diverse psychiatric disorders impact different parts of the pathway to suicide attempts. These findings will help inform clinical and public health efforts aimed at suicide prevention in Mexico and other developing countries.

\section{Keywords}

suicide; suicide attempt; risk factors; epidemiology; survey; psychiatric disorder

Suicidal behaviors, including suicide ideation, plans, and attempts, are prevalent around the world, and psychiatric disorders are one of the strongest and most consistent risk factors across many different countries (Nock et al., 2008). The bulk of the evidence on this risk factor, though, is from studies conducted in developed Western countries. In such countries, mood disorders and especially major depression have emerged as key predictors of suicidality (Kessler et al., 1999; Nock and Kazdin, 2002) and as a result have had preeminence in programs to detect and treat patients with suicidality (Mann et al., 2005; U.S. Public Health Service, 1999).

New results from both developed and developing countries suggest that these results may not generalize to all countries. According to Nock et al. (Nock et al., 2008), although several consistent risk factors for suicidality emerged cross-nationally, an exception was that mood disorders were the strongest diagnostic predictors in developed countries while impulse-control disorders were the strongest predictors in developing countries. Moreover, there is evidence that although a risk index to detect 12-month suicide attempts for developed and developing countries performs equally well in both group of nations, diverse 12-month DSM-IV mental disorders should be selected for developed and developing countries to tailor an appropriate index (Borges et al., in press). For example, results from a national survey of suicidality in Mexico (Borges et al., 2007) suggest that substance use and impulse-control disorders (i.e., not mood disorders) are actually the strongest predictors in this country. Reports from other developing countries such as South Africa, Nigeria, Ukraine, Israel and China (Bromet et al., 2007; Gureje et al., 2007; Joe et al., 2008; Lee et al., 2007; Levinson et al., 2007) also suggest that psychiatric disorders other than depression may be most useful in predicting suicidality.

A key limitation in most prior studies in this area is that they rely largely on tests of bivariate associations between individual disorders and suicidal behavior (Bostwick and Pankratz, 2000; Kessler et al., 1999; Nock et al., 2008; Phillips et al., 2004; Weissman et al., 1989). Because mental disorders are highly comorbid (Kessler et al., 2005), it is possible that many of the observed bivariate associations are due to the effects of only a small number of disorders. New research in the US using the data from the National Comorbidity Survey-Replication (NCS-R)(Nock et al., 2009a) goes beyond simple bivariate associations to present more elaborate multivariate models that account for psychiatric comorbidity and decompose, 1) which disorders are uniquely associated with suicide attempts and 2) whether different disorders may be related to different parts of the pathway to suicide. These authors found that in the US depression predicts suicide ideation; however, disorders characterized by severe anxiety/agitation (e.g., PTSD) and poor impulse-control (e.g., conduct disorder, substance disorders) predict which suicide ideators go on to make a suicide plan or attempt. Subsequent research has shown a similar pattern using data from 21 different countries around the world 
(Nock et al., 2009b). Given that most prior research on suicidal behaviors has been conducted in developed countries, the purpose of the current study was to examine these effects in greater detail within a developing country.

The data reported here are from the Mexican National Comorbidity Survey (M-NCS) (MedinaMora et al., 2005), a nationally representative household survey of adults residing in urban areas in Mexico (roughly 75\% of the national population). Following prior work in the NCS$\mathrm{R}$ (Nock et al., 2009a) and cross-cultural analyses in the context of the World Mental Health Surveys (Nock et al., 2009b) the focus here is to examine the unique associations between psychiatric disorders and suicidal behavior in a developing country (i.e., Mexico), to test the effects of comorbidity on suicidal behavior, and to decompose the associations between psychiatric disorders and suicidal behavior by considering effects of psychiatric disorders on multiple forms of suicidal behavior (i.e., suicide ideation, suicide plans, and suicide attempts).

\section{MATERIALS AND METHODS}

\section{Sample}

The M-NCS is part of the World Health Organization's (WHO) World Mental Health (WMH) Survey Initiative (Demyttenaere et al., 2004; Kessler and Ustun, 2004), a series of coordinated community epidemiological surveys of psychiatric disorders carried out in over two dozen countries throughout the world (www.hcp.med.harvard.edu/wmh). The survey was based on a stratified, multistage area probability sample of non-institutionalized persons aged 18 to 65 years living in urban areas (population 2,500+) of Mexico. About 75\% of the Mexican population is urban and meets the above definition. Data collection took place in two phases from September 2001 through May 2002. The response rate was 76.6\%, for a total of 5,826 interviews, well above the original targeted sample size of 5,000 interviews. Forty four respondents without information on key survey identification variables were deleted, leaving a final sample of 5,782 respondents.

All respondents were administered a Part I interview and a selected sub-sample of 2,362 received a Part II interview which included questions on risk factors and supplemental psychiatric disorders. The sample receiving Part II consisted of all respondents who screened positive for any disorder on Part I plus a probability subsample of other Part I respondents. There was a random selection process embedded into a computer algorithm for the selection of those negative in the first phase of the survey. About one third of those who scored negative in the Part I interview were randomly assigned to Part II interview. All interviews were conducted at the respondent's home after a careful description of the study goals was provided and informed consent was obtained. No financial incentives were given for respondents' participation. All recruitment and consent procedures were approved by the ethics committee of the National Institute of Psychiatry. Additional details of this study and sample have been published elsewhere (Medina-Mora et al., 2005).

\section{Measures}

Suicidal behaviors and potential risk factors were assessed using Version 3.0 of the WHOCIDI a fully structured lay-administered interview (Kessler and Ustun, 2004; Robins et al., 1988). This structured interview was administered face-to-face using a lap-top computer version that yielded DSM-IV diagnoses. The CIDI used in Mexico was based on the translation of the instrument into Spanish according to WHO recommendations, utilizing material currently in use in Spanish (ICD-10, DSM-IV) and previous translations of the Diagnostic Interview Schedule and earlier versions of the CIDI. These earlier instruments showed good performance in validity studies in Mexico (Caraveo et al., 1991; Caraveo et al., 1998) and in other Spanish- speaking countries (Wittchen, 1994). The fieldwork was conducted by Berumen 
and Associates, an established survey research firm in Mexico that employed a group of interviewers who had received training in the CIDI according to the WHO protocol stipulated for participating WMH countries.

Suicidal behavior-The WHO CIDI contains a module that assesses several different suicidal behaviors consistent with prior recommendations and definitions (O'Carroll et al., 1996), such as: suicide ideation ("Have you ever seriously thought about committing suicide?"), suicide plans ("Have you ever made a plan for committing suicide?"), and suicide attempts ("Have you ever attempted suicide?"). Based on evidence that reports of such potentially embarrassing behaviors are higher in self-administered than intervieweradministered surveys (Turner et al., 1998), these questions were printed in a self-administered booklet and referred to by letter. Interviews assessed the lifetime presence and age-of-onset of each outcome.

DSM-IV psychiatric disorders-Respondent disorders were assessed using the WHO CIDI (Robins et al., 1988). The diagnostic assessment included measurement of DSM-IV anxiety (panic disorder, generalized anxiety disorder, specific phobia, social phobia, posttraumatic stress disorder, childhood-adult separation anxiety disorder, agoraphobia without panic disorder), mood (major depressive disorder, dysthymia, bipolar disorder), impulsecontrol (oppositional-defiant disorder, conduct disorder, attention deficit/hyperactivity disorder), and substance use (alcohol abuse or dependence, drug abuse or dependence) disorders. Organic exclusion rules were used in making all respondent diagnoses. Prior studies using clinical reappraisal interviews found CIDI diagnoses to have generally good concordance with blinded diagnoses based on the Structured Clinical Interview for DSM-IV (First et al., 2002) in a probability sub-sample of respondents from the US survey (Kessler et al., 2005).

Statistical analysis-Cross-tabulations were used to estimate the prevalence of temporally prior psychiatric disorders among respondents with suicide ideation and attempts. Discretetime survival analysis with time-varying covariates (Efron, 1988) was used to study retrospectively assessed diagnostic correlates of each suicidal behavior (Borges et al., 2000; Kessler et al., 1999). Survival coefficients were converted to odd-ratios (OR's) for ease of interpretation. The 95\% confidence intervals (CI's) of the OR's are also reported and have been adjusted for design effects. Standard errors (SE) and significance tests were estimated using the Taylor series method (Wolter, 1985) with SUDAAN (2002) software to adjust for the weighting and clustering of the data. Multivariate significance was evaluated using Wald $\chi^{2}$ tests based on design-corrected coefficient variance-covariance matrices. Statistical significance was evaluated using two-tailed .05-level tests.

Survival models examining the relations among psychiatric disorders, comorbidity, and suicidal behaviors proceeded incrementally, and the logic and methods used are defined in greater detail elsewhere (Nock et al., 2009a). First, we fitted bivariate models in which only one psychiatric disorder was considered at a time, as usual in the field. Next, we fitted multivariate models that included all psychiatric disorders simultaneously to predict each suicidal behavior. Finally, we also estimated a series of models that allowed for multiplicative interactions among comorbid disorders. The first one was a model that included summary dummy predictor variables for total number of comorbid disorders experienced by each respondent (e.g., separate dummy predictor variables to distinguish respondents with exactly two disorders, exactly three, ..., etc.). This model assumed that interactions were constant across types of disorder and were influenced only by number of disorders. Next we fitted more complex models that allowed for separate interactions between each type of disorder and number of comorbid disorders. The simple model that assumed constant interactions was a good approximation of the data, so we focused on that model in subsequent analyses. Assuming that the relationship between psychiatric disorders and suicidality was causal, we then 
estimated population attributable risk proportions (PARPs) due to each psychiatric disorder and to all disorders combined based on the results of that simple interaction model. PARPs represent the proportion of cases with a suicide attempt that would be prevented if specified predictor variables were eliminated, assuming causal relations between predictor variables and suicide attempts.

\section{RESULTS}

\section{Lifetime prevalence of psychiatric disorders among those with suicidal behavior}

Approximately half of all people who have seriously considered killing themselves (48.8\%) and two-thirds who make a suicide attempt $(65.2 \%)$ reported having a prior psychiatric disorder (Table I). Among respondents with suicide ideation, the prevalence of a psychiatric disorder is higher among those making a planned suicide attempt (68.6\%) than among those making an unplanned (i.e., impulsive) attempt (57.7\%).

\section{Associations between psychiatric disorders and subsequent suicide attempts}

The results of the three models testing the associations between prior psychiatric disorders and suicide attempt in the M-NCS are presented in Table II. Bivariate survival models show that each of the 15 lifetime DSM-IV/CIDI disorders examined is significantly associated with increased risk of the subsequent first onset of a suicide attempt, with ORs from a low of 4.2 (panic) to a high of 20.8 (conduct disorder)(Table II, Column 1). Overall, anxiety disorders have the lowest ORs (5.9) while substance use disorders have the highest ORs (13.5). In multivariate models including all disorders, there is a large decrease in all ORs estimated (Table II, Column 2). Although most ORs are still over the null (with the exception of panic), only seven remained statistically significant. The largest OR was again for conduct disorder (6.3). Next, simple interactive multivariate models were estimated that included one dummy variable for each of the 15 disorders plus additional dummy variables for each number of disorders (e.g., exactly one prior disorder, exactly two, etc.). The ORs for individual disorders in these models can be interpreted as the relative odds of a subsequent suicide attempt among respondents with a pure disorder (i.e., only this one disorder) versus those with no disorders. Consistent with the prior model, all pure disorders estimated in this interactive model have increased but lowered ORs when compared to the bivariate model, with eight of them statistically significant, ranging from 1.8 (social phobia) to 6.7 (conduct disorder)(Table II, Column 3).

\section{Associations between psychiatric comorbidity and subsequent suicide attempts}

Next we evaluated a model in which the only substantive predictors were dummy variables for number of prior disorders (Table III). A strong positive association was found between these predictors and subsequent suicide attempt, with ORs ranging from a low of 4.2 for one disorder (compared to respondents with no disorders) up through 39.3 for four or more disorders. The ORs for high numbers of disorders in a model that also included predictors for the 15 types of disorders (i.e., as in Table II) showed the existence of sub-additive effects of comorbidities involving large numbers of disorders. In other words, as the number of comorbid disorders goes up, the relative odds of a suicide attempt increases at a decreasing rate.

\section{Unique associations among psychiatric disorders and each suicidal outcome}

We next examined the unique associations between each disorder and each of the five suicidal behaviors measured (Table IV). Consistent associations are seen between each disorder and suicide ideation (all ORs are positive and 10 are statistically significant). Conditional associations with suicide plans among ideators are both less consistent and less powerful (10 of the 15 ORs positive, only 2 statistically significant). Conditional associations with attempts 
among planners tended to be more positive and with larger ORs than those among unplanned attempts, with conduct disorder showing the only statistically significant $\mathrm{OR}(\mathrm{OR}=15.5)$. Among unplanned attempts nine ORs were below the null and one of them was statistically significant (conduct disorder, $\mathrm{OR}=0.2$ ). Also, among unplanned attempts general anxiety disorder had a high and elevated OR (14.0).

\section{Population attributable risk proportions}

We calculated population attributable risk proportions (PARPs) to test population-level effects. The PARP estimates reveal that the predictive effects of psychiatric disorders on suicide attempts are largely due to effects on ideation rather than on the transitions from ideation to plans or attempts (Table V). For all disorders combined, the PARPs suggest that almost threefourths $(73.2 \%)$ of all suicide attempts are associated with prior DSM-IV/CIDI disorders and that this strong aggregate association is due largely to the association between disorders and suicide ideation (76.4\%), with much smaller PARPs of disorders predicting the onset of a suicide plan among ideators $(0.7 \%)$, attempts among ideators with a plan $(14.6 \%)$, and attempts among ideators without a plan (36.2\%). Anxiety disorders play the largest role in accounting for the onset of ideation and attempts, followed closely by mood disorders. Anxiety and substance use disorders play the largest roles in accounting for attempts among ideators without a plan.

\section{DISCUSSION}

In this nationally representative urban sample of respondents from Mexico, we found that a psychiatric disorder was present in $48.8 \%$ of those with a suicide ideation and in $65.2 \%$ of those with an attempt. Although all disorders were associated with increased odds of a subsequent suicide attempt in bivariate models, more elaborate multivariate models that adjusted for comorbidity suggested that conduct disorder and alcohol abuse or dependence were the most important predictors in this sample, increasing the likelihood of an attempt by about six times. Other individual disorders, mainly anxiety disorders, followed in the list of predictors with increasing ORs of about $2-3$ fold. In multivariate models, mood disorders produced increased but non-significant ORs for suicide attempt. Most associations of psychiatric disorders with suicidality were due to the prediction of suicidal ideation. Very few disorders accounted for the transition between ideation and a suicide plan (only oppositionaldefiant disorder and alcohol abuse or dependence), or between ideation and planned attempt (only conduct disorder) and between ideation and unplanned attempt (conduct disorder reduced the risk and general anxiety disorder increased it). The inverse association between conduct disorder and unplanned attempts is surprising and we recommend caution in weighting this finding too heavily given that the seven other associations between conduct disorder and suicidal behaviors tested in this study were all positive and consistently among the strongest ORs observed in this study. Results suggested that interventions to reduce psychiatric disorders would have a high impact on suicide ideation ( $76 \%$ reduction) and attempts (73\% reduction).

This study in a developing country confirms findings from psychological autopsy studies on the high prevalence of psychiatric disorders among those with a suicide attempt, suggesting that psychiatric disorders should be target for suicidal interventions even in countries where low socioeconomic status and unemployment have been pointed as key risk factors (OrtizHernandez et al., 2007). The prevalence of psychiatric disorders among suicide attempters in Mexico is lower than the prevalence reported in the US (79.6\%)(Nock et al., 2009a); however, this maybe due to the overall higher prevalence of psychiatric disorders in the US compared to Mexico (Demyttenaere et al., 2004; Nock et al., 2009a) and not to a low relative risk associated with psychiatric disorders in Mexico. 
Our analyses replicate the findings from a prior study in the US (Nock et al., 2009a), showing that bivariate associations of psychiatric disorders with suicidality are limited because there are large effects of comorbidity on individual disorders. The current study extends earlier work by illuminating the larger role that conduct disorder and alcohol use disorder play in the onset of suicidal behavior among Mexicans. Other reports from individual developing countries participating in the WMH Surveys (Demyttenaere et al., 2004) also have found larger than expected roles of impulse-control, substance use, and anxiety disorders in the onset of suicidal behavior in South Africa (Joe et al., 2008), Nigeria (Gureje et al., 2007), Ukraine (Bromet et al., 2007), and Israel (Levinson et al., 2007). In China, more consistent with reports from developed Western countries, mood and anxiety disorders have emerged as the strongest diagnostic predictors of suicidal behavior (Lee et al., 2007). On the other hand, in developed European countries participating in the WMH Surveys (Bernal et al., 2006) depression, dystimia, GAD and PTSD were the disorders more related to suicide ideation and attempt. Whether this series of results will hold in these individual countries when more complex models are used is a matter for future work, but merged data from the WMH Surveys suggest that, as a group, in developing countries other disorders were stronger predictors of suicide attempts including: conduct disorder, oppositional-defiant disorder, intermittent-explosive disorder, drug and alcohol abuse, and PTSD (Nock et al., 2009b). The reasons for this difference in the risk of individual disorders in developed and developing countries are not known and represent an important direction for future suicide research.

The risk for suicide attempt was strongly related to the number of disorders, as previously reported (Beautrais et al., 1996, Kessler et al., 1999, Nock et al., 2008). As in the US sample (Nock et al., 2009a), the current analyses add to the literature in showing that despite this strong dose-response relation, sub-additive interactive effects were observed, suggesting that there is a decay in the predictive power of comorbidity as the number of comorbidities gets larger. Analysis of possible factors associated with these large levels of comorbidity, such as increasing levels of stress and large amounts of negative lifetime experiences that may lead to a high likelihood of suicidal behavior will be future topics of our inquiries. Whether the doseresponse found for number of disorders and risk of suicidality could be applied to completed suicide is a matter of further discussion, beyond the scope of this report. Nevertheless, some caution for simple generalization of our findings is needed, since at least one recent report on psychiatric comorbidity and risk of completed suicide failed to find a similar dose-response as reported here (Walby et al., 2006).

While risk factor analyses pointed to substance use and impulse-control disorders as the main psychiatric disorders to consider in Mexico, PARP results shifted the focus to anxiety and mood disorders. This is consistent with the similar ORs observed among several disorders in this report (Table IV) and to the fact that anxiety disorders have, overall, much higher prevalence in Mexico than other psychiatric disorders (Medina-Mora et al., 2007,Medina-Mora et al., 2005). The complex picture of diverse psychiatric disorders impacting on suicidality in Mexico, both on clinical and public health practice, needs to be carefully considered when implementing preventive strategies in the country. Although it is clear that suicide prevention efforts should include a focus on screening and treating psychiatric disorders in both developed and developing countries, simply translating experiences and manuals for public health control of suicidality from other, usually developed nations, does not seem appropriate in the light of these results.

The study findings must be evaluated in the context of several study limitations. First, the MNCS is a household survey that excluded homeless and institutionalized people, both populations known to have high prevalence of suicidal behavior (Desai et al., 2003). Second, the diagnostic instrument used in the M-NCS did not include an assessment of all DSM-IV disorders, some of which have been linked to increased risk of suicidal behaviour and increase 
the comorbidity discussed here, such as schizophrenia and other non-affective psychoses (Harkavy-Friedman et al., 2004; Kessler et al., 1999). Third, validity and reliability data were not obtained on the measures of ideation, plans and attempts. Fourth, although we examined suicide ideation, plans, and attempts, we did not measure other important self-injurious behaviors such as suicide gestures (e.g., Nock and Kessler, 2006) and non-suicidal self-injury (e.g., Nock and Prinstein, 2005), and so the epidemiology of these outcomes awaits further study. Fifth, we did not examine the severity and/or recency of disorders in these models and whether these factors could help explain some (but not all) of the findings regarding the transitions from ideation to attempt. Finally, these analyses used data on retrospectively reported ages of onset that are subject to recall errors, which likely lead the results reported here to be conservative with regard to the magnitude of the problem of nonfatal suicide-related outcomes in Mexico.

\section{Acknowledgments}

The Mexican National Comorbidity Survey (M-NCS) is supported by The National Institute of Psychiatry Ramon de la Fuente (INPRFM-DIES 4280) and by the National Council on Science and Technology (CONACyT-G30544-H), with supplemental support from the Pan American Health Organization (PAHO). Collaborating M-NCS investigators included Maria-Elena Medina-Mora (Principal Investigator), Guilherme Borges, and Carmen Lara, all from The Mexican Institute of Psychiatry and the Metropolitan Autonomous University (Guilherme Borges). The Mexican National Comorbidity Survey (M-NCS) is carried out in conjunction with the World Health Organization World Mental Health (WMH) Survey Initiative. We thank the WMH staff for assistance with instrumentation, fieldwork, and data analysis. These activities were supported by the United States National Institute of Mental Health (R01MH070884, MH077883), the John D. and Catherine T. MacArthur Foundation, the Pfizer Foundation, the US Public Health Service (R13-MH066849, R01-MH069864, and R01 DA016558), the Fogarty International Center (FIRCA R03-TW006481), the Pan American Health Organization, the Eli Lilly \& Company Foundation, OrthoMcNeil Pharmaceutical, Inc., GlaxoSmithKline, and Bristol-Myers Squibb. A complete list of WMH publications can be found at http://www.hcp.med.harvard.edu/wmh/.

Role of Funding Source.

Authors state that the study sponsor(s) had no involvement in design; in the collection, analysis and interpretation of data; in the writing of the report; or in the decision to submit the paper for publication.

\section{REFERENCES}

Beautrais AL, Joyce PR, Mulder RT, Fergusson DM, Deavoll BJ, Nightingale SK. Prevalence and comorbidity of mental disorders in persons making serious suicide attempts: a case-control study. Am. J. Psychiatry 1996;153:1009-1014. [PubMed: 8678168]

Borges G, Nock MK, Medina-Mora ME, Benjet C, Lara C, Chiu WT, Kessler RC. The epidemiology of suicide-related outcomes in Mexico. Suicide Life Threat. Behav 2007;37:627-640. [PubMed: 18275369]

Borges G, Walters EE, Kessler RC. Associations of substance use, abuse, and dependence with subsequent suicidal behavior. Am. J. Epidemiol 2000;151:781-789. [PubMed: 10965975]

Borges G, Nock MK, Josep M, Haro-Abad JM, Hwang I, Sampson NA, Alonso J, Andrade LH, Angermeyer LC, Beautrais A, Bromet E\$, Bruffaerts R, de Girolamo G, Florescu S, Gureje O, Hu C, Karam EG, Kovess-Masfety V, Lee S, Levinson D, Medina-Mora ME, Ormel J, Posada-Villa J, Sagar R, Tomov T, Uda H, Williams DR, Kessler RC. Twelve Month Prevalence of and Risk Factors for Suicide Attempts in the WHO World Mental Health Surveys. Clinical Psychiatry. In press.

Bostwick JM, Pankratz VS. Affective disorders and suicide risk: a reexamination. Am. J. Psychiatry 2000;157:1925-1932. [PubMed: 11097952]

Bromet EJ, Havenaar JM, Tintle N, Kostyuchenko S, Kotov R, Gluzman S. Suicide ideation, plans and attempts in Ukraine: findings from the Ukraine World Mental Health Survey. Psychol. Med 2007;37:807-819. [PubMed: 17288636]

Caraveo AJ, González C, Ramos L. The concurrent validity of the DIS: experience with psychiatric patients in Mexico City. Hispanic J. Behav. Sci 1991;13:63-77. 
Caraveo AJ, Martínez N, Rivera E. Un modelo para estudios epidemiológicos sobre la salud mental y la morbilidad psychiátrica [A model for epidemiological, studies on mental health and psychiatric morbidity]. Salud Mental Marzo 1998;21:48-57. Spanish.

Demyttenaere K, Bruffaerts R, Posada-Villa J, Gasquet I, Kovess V, Lepine JP, Angermeyer MC, Bernert S, de Girolamo G, Morosini P, Polidori G, Kikkawa T, Kawakami N, Ono Y, Takeshima T, Uda H, Karam EG, Fayyad JA, Karam AN, Mneimneh ZN, Medina-Mora ME, Borges G, Lara C, de Graaf R, Ormel J, Gureje O, Shen Y, Huang Y, Zhang M, Alonso J, Haro JM, Vilagut G, Bromet EJ, Gluzman S, Webb C, Kessler RC, Merikangas KR, Anthony JC, Von Korff MR, Wang PS, Brugha TS, AguilarGaxiola S, Lee S, Heeringa S, Pennell BE, Zaslavsky AM, Ustun TB, Chatterji S. Prevalence, severity, and unmet need for treatment of mental disorders in the World Health Organization World Mental Health Surveys. JAMA 2004;291:2581-2590. [PubMed: 15173149]

Desai RA, Liu-Mares W, Dausey DJ, Rosenheck RA. Suicidal ideation and suicide attempts in a sample of homeless people with mental illness. J. Nerv. Ment. Dis 2003;191:365-371. [PubMed: 12826917]

Efron B. Logistic regression, survival analysis, and the Kaplan Meier curve. J. Am. Stat. Assoc 1988;83:414-425.

First, MB.; Spitzer, RL.; Gibbon, M.; Williams, JBW. Structured Clinical Interview for DSM-IV-TR Axis I Disorders, Research Version, Non-Patient Edition (SCID-I/NP). Biometrics Research, New York State Psychiatric Institute; New York, NY: 2002.

Gureje O, Kola L, Uwakwe R, Udofia O, Wakil A, Afolabi E. The profile and risks of suicidal behaviours in the Nigerian Survey of Mental Health and Well-Being. Psychol. Med 2007;37:821-830. [PubMed: 17349104]

Harkavy-Friedman JM, Nelson EA, Venarde DF, Mann JJ. Suicidal behavior in schizophrenia and schizoaffective disorder: examining the role of depression. Suicide Life Threat. Behav 2004;34:6676. [PubMed: 15106889]

Joe S, Stein DJ, Seedat S, Herman A, Williams DR. Prevalence and correlates of non-fatal suicidal behaviour among South Africans. Br. J. Psychiatry 2008;192:310-311. [PubMed: 18378997]

Kessler RC, Borges G, Walters EE. Prevalence of and risk factors for lifetime suicide attempts in the National Comorbidity Survey. Arch. Gen. Psychiatry 1999;56:617-626. [PubMed: 10401507]

Kessler RC, Chiu WT, Demler O, Merikangas KR, Walters EE. Prevalence, severity, and comorbidity of 12-month DSM-IV disorders in the National Comorbidity Survey Replication. Arch. Gen. Psychiatry 2005;62:617-627. [PubMed: 15939839]

Kessler RC, Ustun TB, The World Mental Health (WMH); Survey Initiative Version of the World Health Organization (WHO); Composite International Diagnostic Interview (CIDI). Int. J. Methods Psychiatr. Res 2004;13:93-121. [PubMed: 15297906]

Lee S, Fung SC, Tsang A, Liu ZR, Huang YQ, He YL, Zhang MY, Shen YC, Nock MK, Kessler RC. Lifetime prevalence of suicide ideation, plan, and attempt in metropolitan China. Acta Psychiatr. Scand 2007;116:429-437. [PubMed: 17997722]

Levinson D, Haklai Z, Stein N, Polakiewicz J, Levav I. Suicide ideation, planning and attempts: results from the Israel National Health Survey. Isr. J. Psychiatry Relat. Sci 2007;44:136-143. [PubMed: 18080650]

Mann JJ, Apter A, Bertolote J, Beautrais A, Currier D, Haas A, Hegerl U, Lonnqvist J, Malone K, Marusic A, Mehlum L, Patton G, Phillips M, Rutz W, Rihmer Z, Schmidtke A, Shaffer D, Silverman M, Takahashi Y, Varnik A, Wasserman D, Yip P, Hendin H. Suicide prevention strategies: a systematic review. JAMA 2005;294:2064-2074. [PubMed: 16249421]

Medina-Mora ME, Borges G, Benjet C, Lara C, Berglund P. Psychiatric disorders in Mexico: lifetime prevalence in a nationally representative sample. Br. J. Psychiatry 2007;190:521-528. [PubMed: 17541113]

Medina-Mora ME, Borges G, Lara C, Benjet C, Blanco J, Fleiz C, Villatoro J, Rojas E, Zambrano J. Prevalence, service use, and demographic correlates of 12-month DSM-IV psychiatric disorders in Mexico: results from the Mexican National Comorbidity Survey. Psychol. Med 2005;35:1773-1783. [PubMed: 16300691]

Nock MK, Borges G, Bromet EJ, Alonso J, Angermeyer M, Beautrais A, Bruffaerts R, Chiu WT, de Girolamo G, Gluzman S, de Graaf R, Gureje O, Haro JM, Huang Y, Karam E, Kessler RC, Lepine JP, Levinson D, Medina-Mora ME, Ono Y, Posada-Villa J, Williams D. Cross-national prevalence 
and risk factors for suicidal ideation, plans and attempts. Br. J. Psychiatry 2008;192:98-105. [PubMed: 18245022]

Nock MK, Hwang I, Sampson N, Kessler RC. Mental disorders, comorbidity, and suicidal behaviors: results from the National Comorbidity Survey Replication. Mol. Psychiatry. 2009a

Nock MK, Hwang I, Sampson N, Kessler RC, Angermeyer M, Beautrais A, Borges G, Bromet E, Bruffaerts R, de Girolamo G, de Graaf R, Florescu S, Gureje O, Haro JM, Hu C, Huang Y, Karam EG, Kawakami N, Kovess V, Levinson D, Posada-Villa J, Sagar R, Tomov T, Viana MC, Williams DR. Cross-national analysis of the associations among mental disorders and suicidal behavior: Findings from the WHO World Mental Health Surveys. PLoS Medicine 2009b;6:e1000123. [PubMed: 19668361]

Nock MK, Kazdin AE. Examination of affective, cognitive, and behavioral factors and suicide-related outcomes in children and young adolescents. J. Clin. Child Adolesc. Psychol 2002;31:48-58. [PubMed: 11845650]

Nock MK, Kessler RC. Prevalence of and risk factors for suicide attempts versus suicide gestures: Analysis of the National Comorbidity Survey. J. Abnorm. Psychol 2006;115:616-623. [PubMed: 16866602]

Nock MK, Prinstein MJ. Clinical features and behavioral functions of adolescent self-mutilation. J. Abnorm. Psychol 2005;114:140-146. [PubMed: 15709820]

O'Carroll PW, Berman AL, Maris RW, Moscicki EK, Tanney BL, Silverman MM. Beyond the Tower of Babel: a nomenclature for suicidology. Suicide Life Threat. Behav 1996;26:237-252. [PubMed: 8897663]

Ortiz-Hernandez L, Lopez-Moreno S, Borges G. Desigualdad socioeconómica y salud mental: Revisión de la literatura Latinoamericana [Socioeconomic inequality and mental health: a Latin American literature review]. Cad Saude Publica 2007;23:1255-1272. Spanish. [PubMed: 17546318]

Phillips MR, Yang G, Li S, Li Y. Suicide and the unique prevalence pattern of schizophrenia in mainland China: a retrospective observational study. Lancet 2004;364:1062-8. [PubMed: 15380965]

Robins LN, Wing J, Wittchen HU, Helzer JE, Babor TF, Burke J, Farmer A, Jablenski A, Pickens R, Regier DA, et al. The Composite International Diagnostic Interview: an epidemiologic Instrument suitable for use in conjunction with different diagnostic systems and in different cultures. Arch. Gen. Psychiatry 1988;45:1069-1077. [PubMed: 2848472]

Turner CF, Ku L, Rogers SM, Lindberg LD, Pleck JH, Sonenstein FL. Adolescent sexual behavior, drug use, and violence: increased reporting with computer survey technology. Science 1998;280:867-873. [PubMed: 9572724]

U.S. Public Health Service. The Surgeon General's Call to Action to Prevent Suicide. US Public Health Service; Washington, DC: 1999.

Weissman MM, Klerman GL, Markowitz JS, Ouellette R. Suicidal ideation and suicide attempts in panic disorder and attacks. N. Engl. J. Med 1989;321:1209-1214. [PubMed: 2797086]

Wittchen HU. Reliability and validity studies of the WHO--Composite International Diagnostic Interview (CIDI): a critical review. J. Psychiatr. Res 1994;28:57-84. [PubMed: 8064641]

Wolter, KM. Introduction to Variance Estimation. Springer-Verlag; New York, NY: 1985.

J Affect Disord. Author manuscript; available in PMC 2011 July 1. 


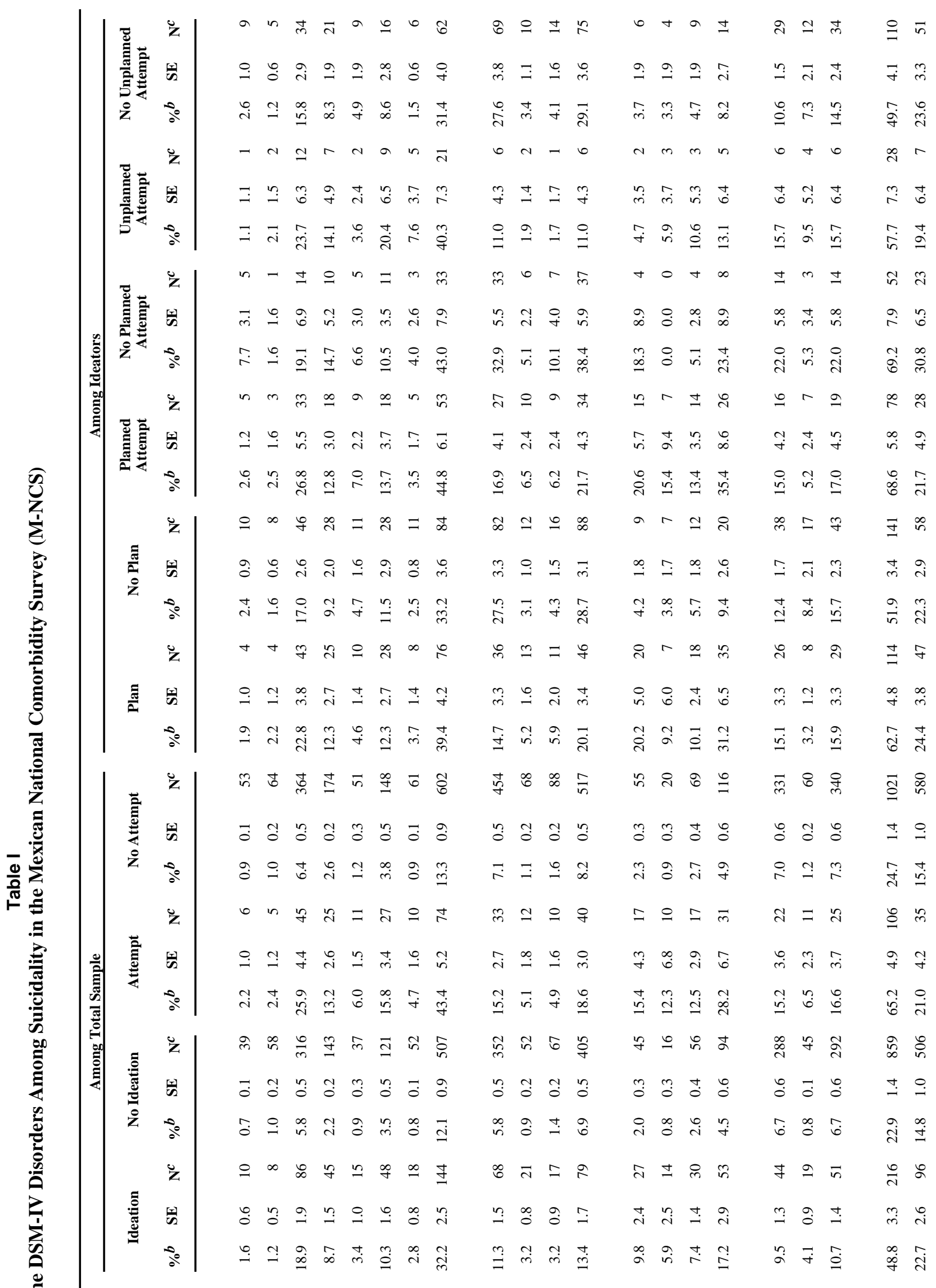

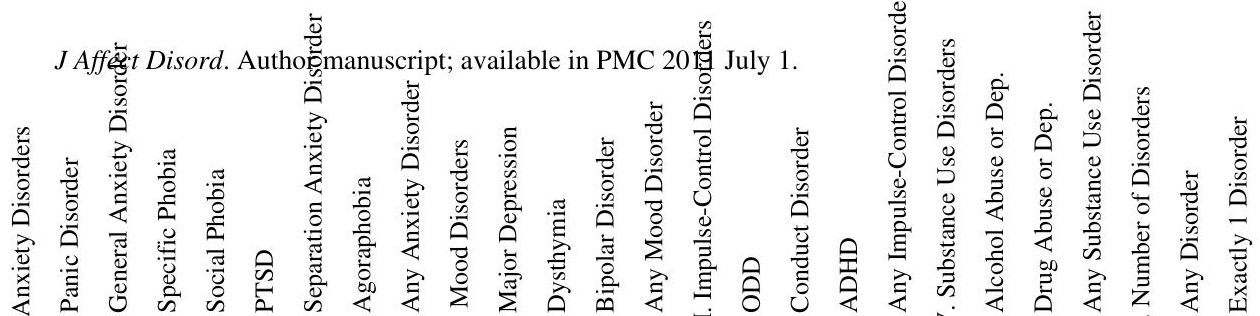




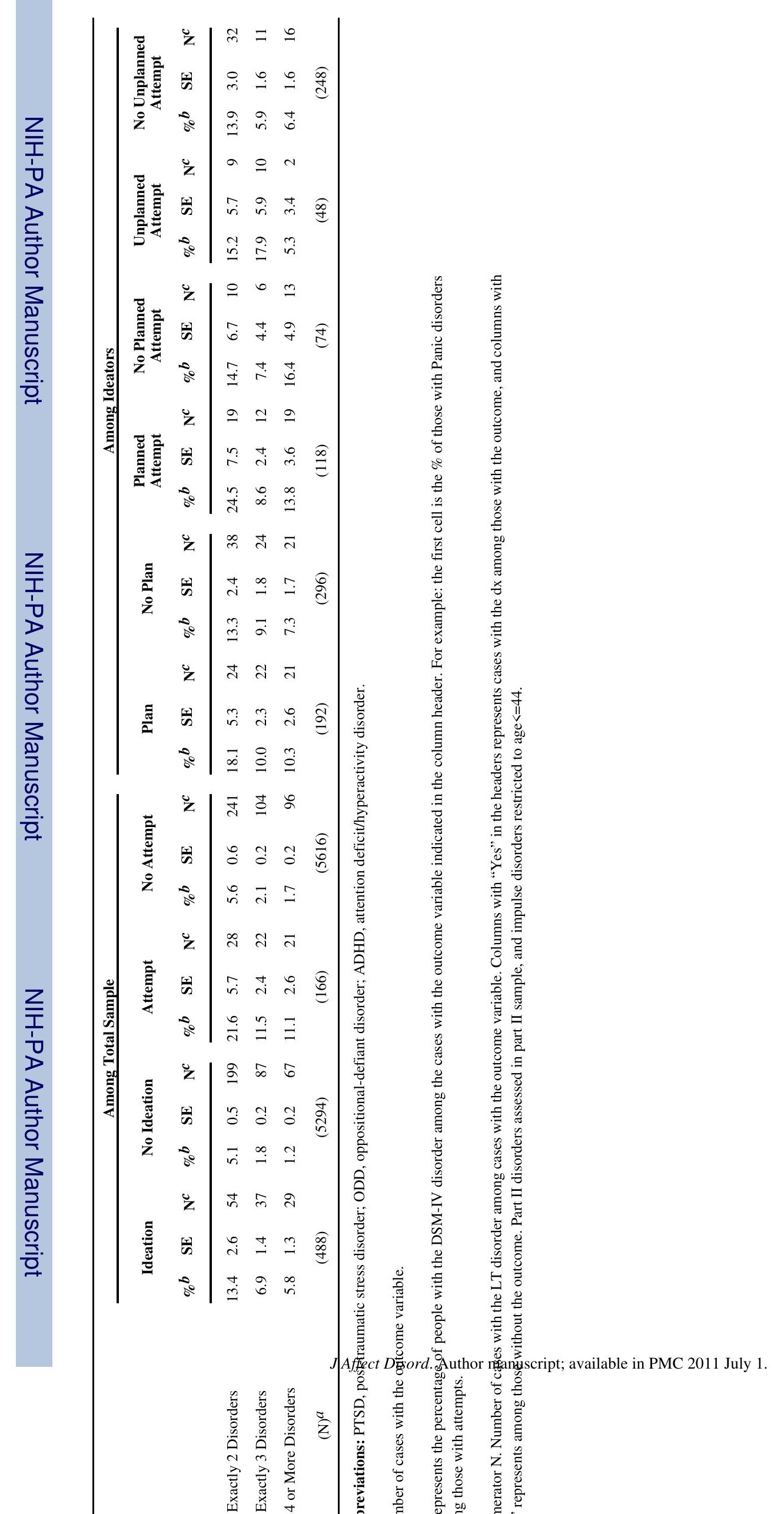



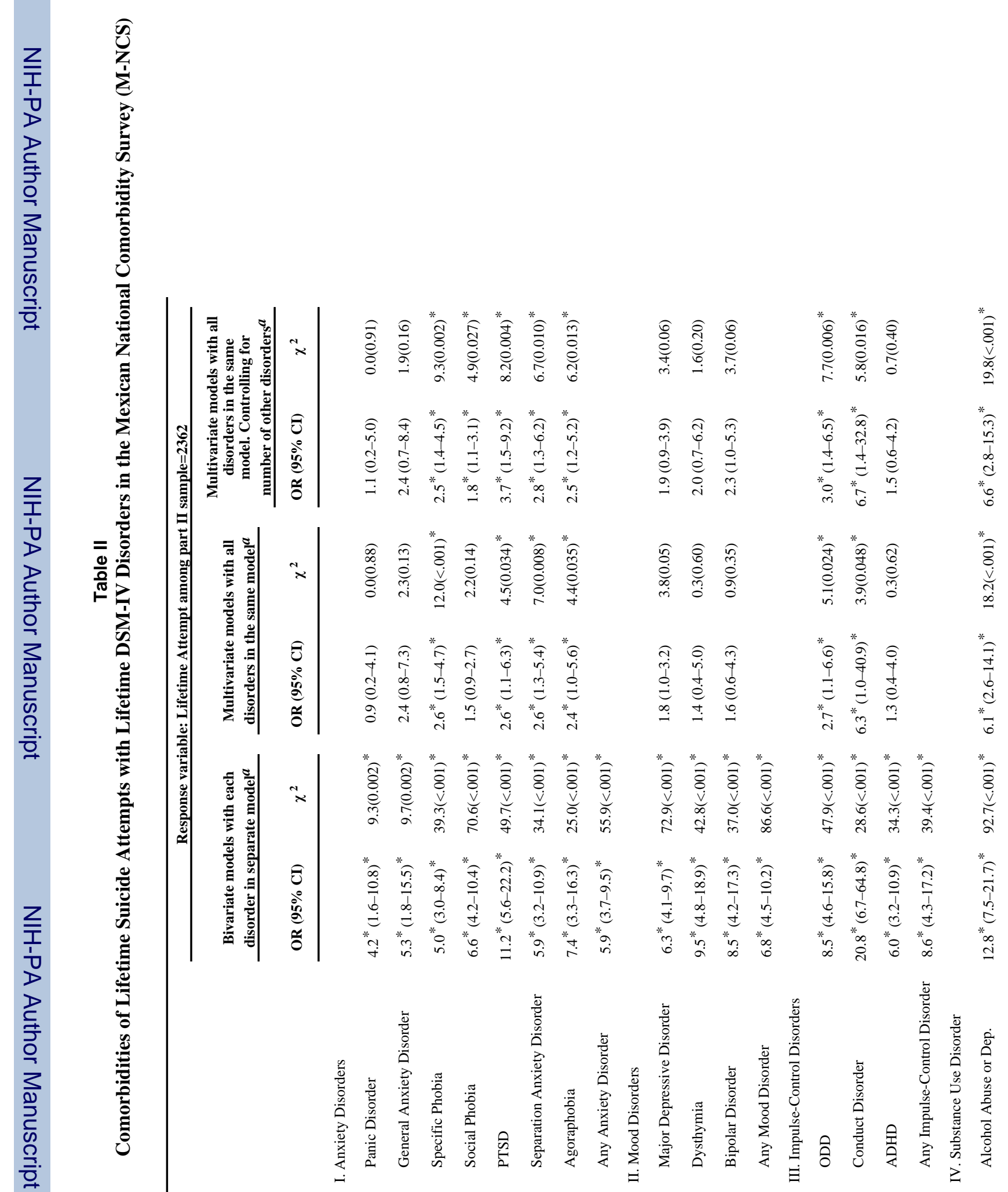

J Affect Disord. Author manuscript; available in PMC 2011 July 1. 


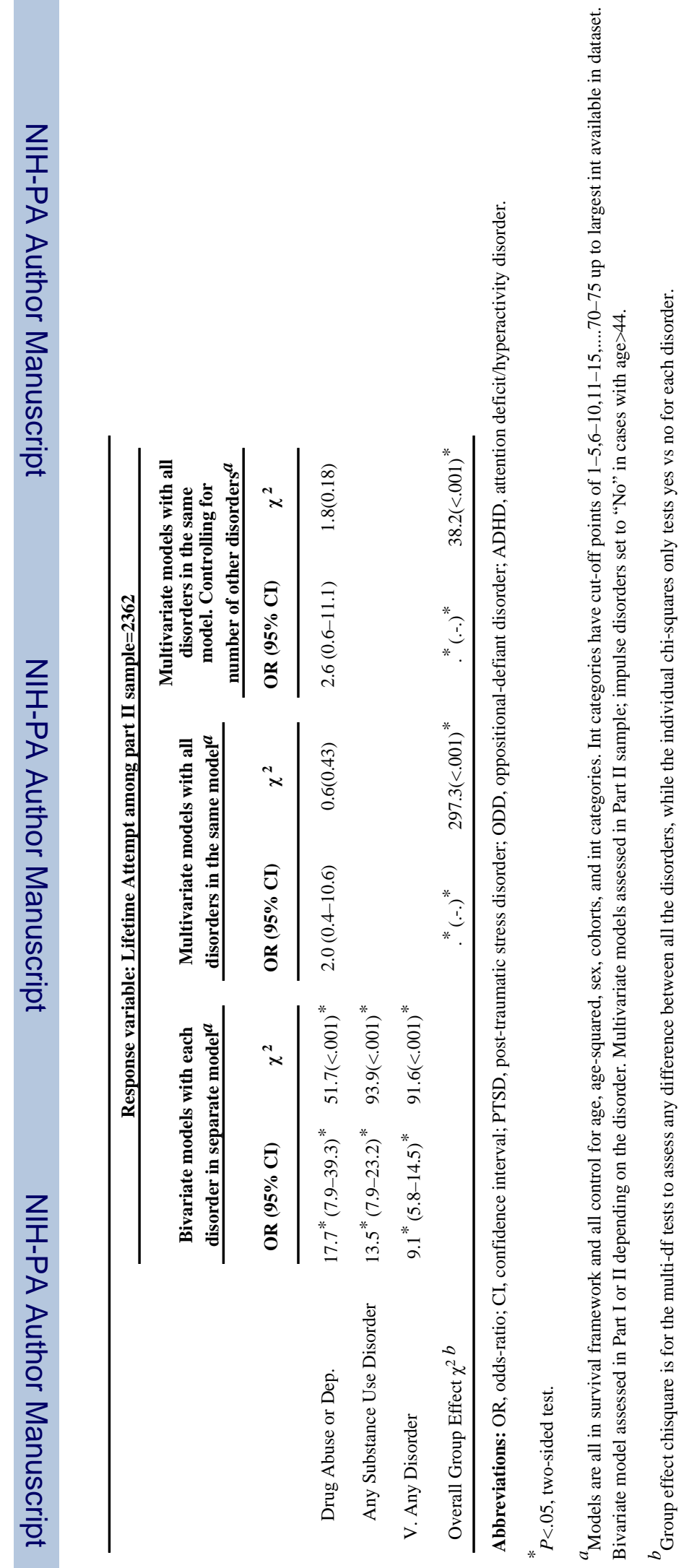

J Affect Disord. Author manuscript; available in PMC 2011 July 1. 


\section{Table III}

Comorbidities of Lifetime Suicide Attempts with Number of Lifetime DSM-IV Disorders in the Mexican National Comorbidity Survey (M-NCS)

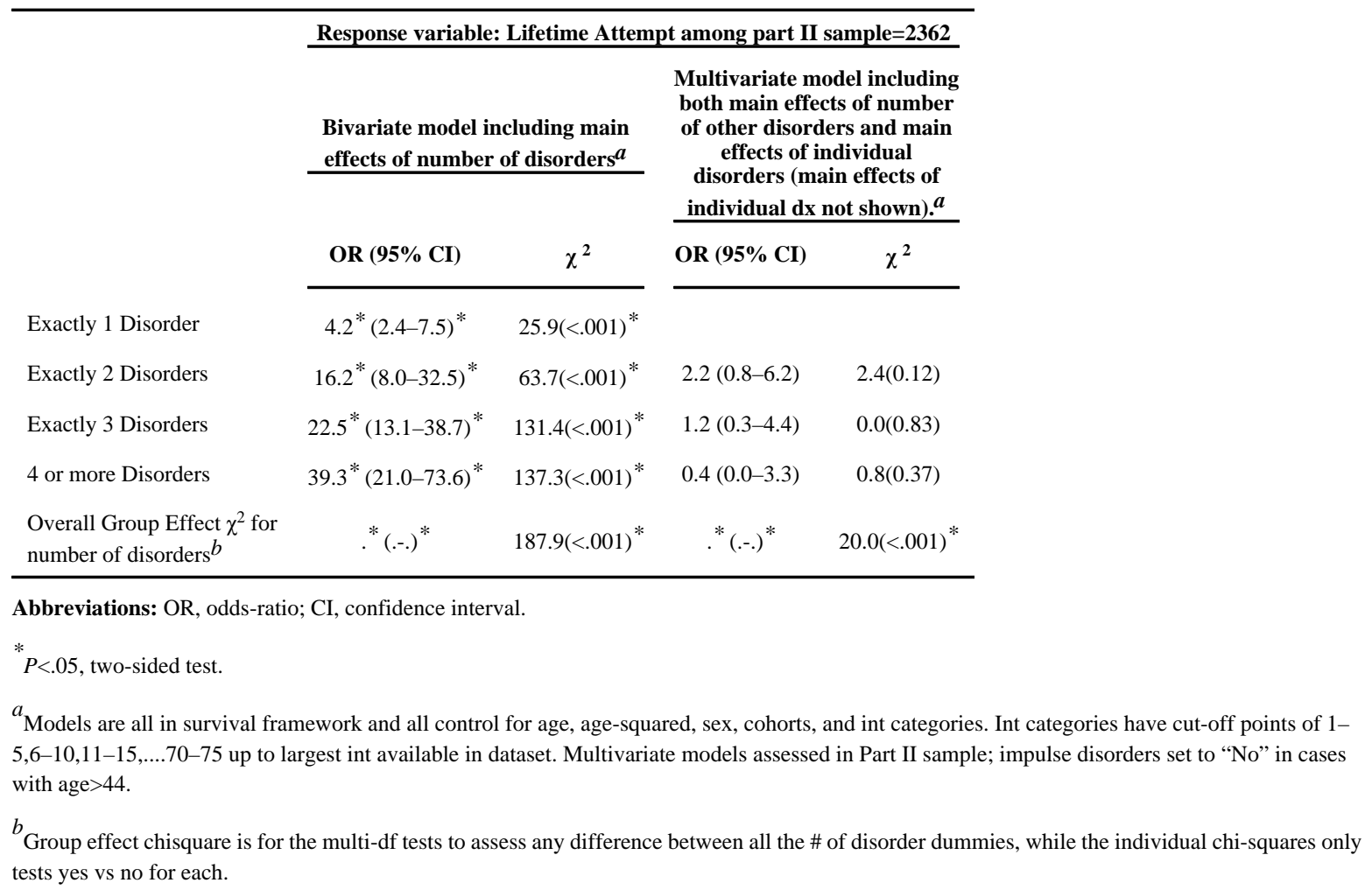



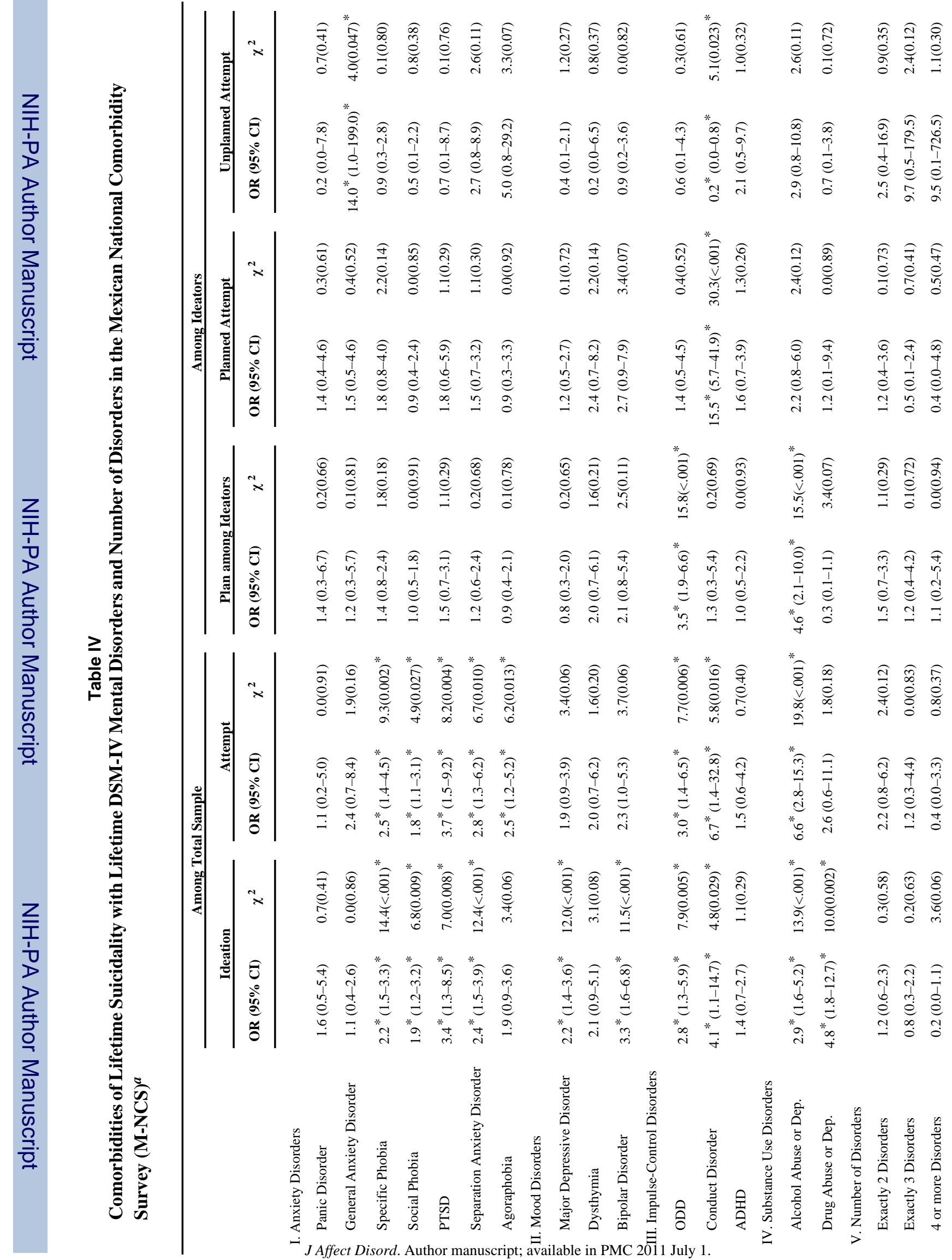


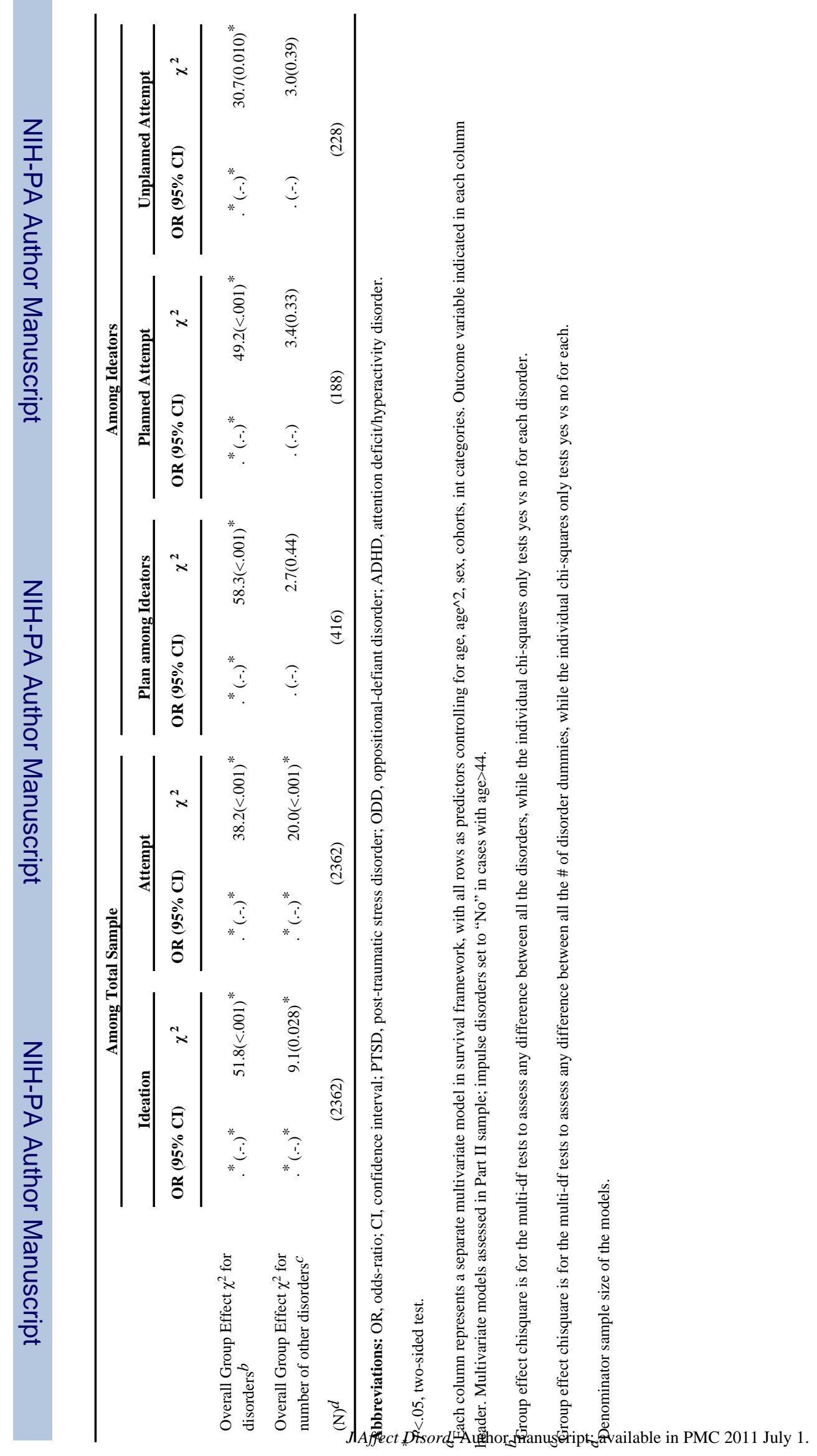




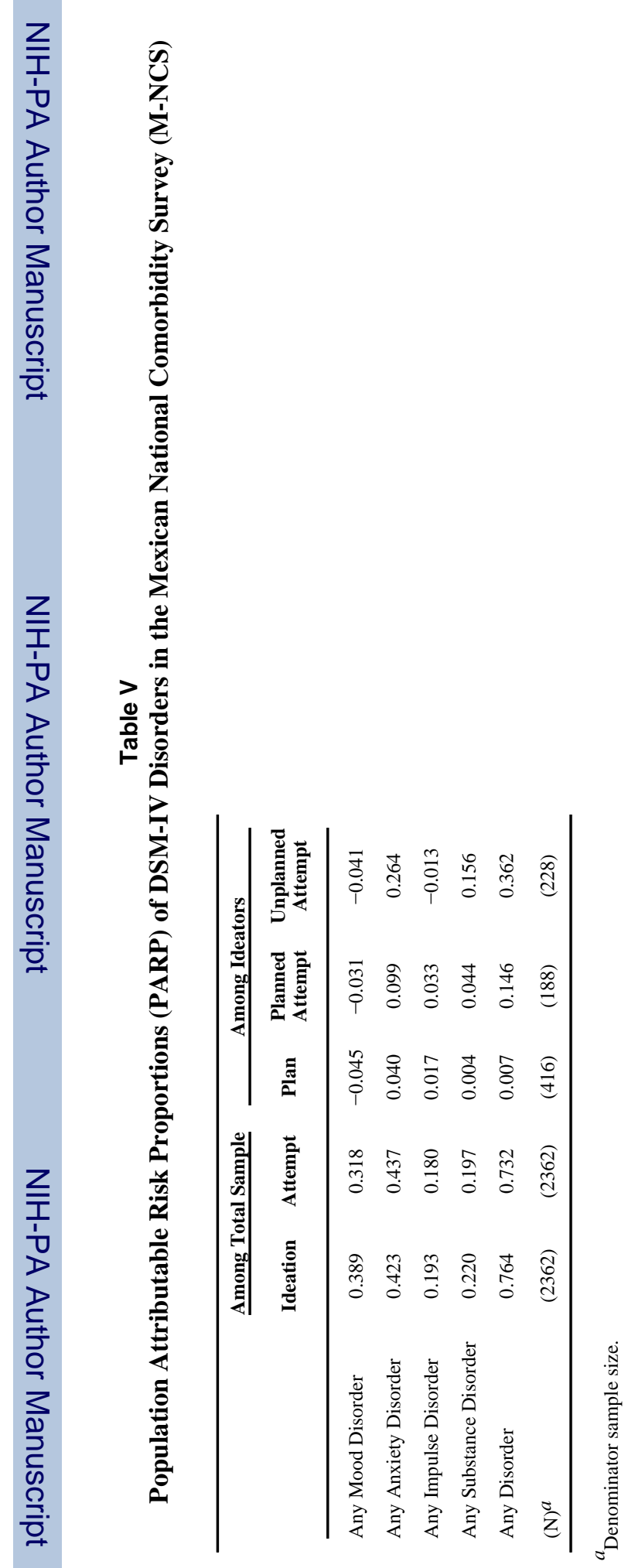

